\title{
Single arm prospective multicenter case series on the use of burst stimulation to improve pain and motor symptoms in Parkinson's disease
}

Krishnan V. Chakravarthy ${ }^{1,2^{*}}$, Rahul Chaturvedi ${ }^{1}$, Takashi Agari ${ }^{3}$, Hirokazu Iwamuro ${ }^{4}$, Rajiv Reddy ${ }^{1}$ and Ayano Matsui ${ }^{5}$

\begin{abstract}
Background: In this study we analyze new clinical data in the use of spinal cord stimulation (SCS) for the treatment of pain and motor symptoms in patients with Parkinson's Disease (PD), as both a singular bioelectric therapy and as a salvage therapy after deep brain stimulation (DBS).

Methods: Fifteen patients were recruited and had percutaneous electrodes implanted at the level of the thoracic or cervical spine. Participants were set to one of three stimulation modes: continuous tonic stimulation, continuous Burst stimulation $(40 \mathrm{~Hz}, 500 \mathrm{~Hz}, 1000 \mu \mathrm{s})$, or cycle mode (on time of 10-15 s, off time of 15-30 s) with Burst (40 Hz, $500 \mathrm{~Hz}, 1000$ us). Patients completed the Visual Analogue Scale (VAS), Unified Parkinson's Disease Rating Scale, SelfRating Depression Scale, Hamilton Depression Rating Scale, Profile of Mood State, 10-meter walking test, and the Timed Up and Go (TUG).

Results: All patients experienced significant improvement in VAS scores with a mean reduction of $59 \%$ across all patients. Patients who chose the cycling burst stimulation parameter had an average $67 \%$ reduction in VAS scores, as compared to the continuous burst parameter group, which had an average $48 \%$ reduction in VAS scores. Seventy-three percent of patients experienced improvement in the 10-meter walk, with an average improvement of $12 \%$. Sixty-four percent of patients experienced clinically relevant improvements in the TUG, with an average improvement of $21 \%$.
\end{abstract}

Conclusions: This study points to the potential utility of SCS to address both pain and certain aspects of motor symptoms in PD patients who have and have not received DBS therapy.

Keywords: Burst simulation, Parkinson disease, Spinal cord stimulation, Dorsal column stimulation, Deep brain stimulation

\footnotetext{
* Correspondence: kvchakravarthy@ucsd.edu

${ }^{1}$ Division of Pain Medicine, Department of Anesthesiology, University of California San Diego Health Center, 9400 Campus Point Dr, La Jolla, San Diego, CA, USA

${ }^{2}$ VA San Diego Health Care, 3350 La Jolla Village Dr, San Diego, CA, USA

Full list of author information is available at the end of the article
}

(c) The Author(s). 2020 Open Access This article is licensed under a Creative Commons Attribution 4.0 International License, which permits use, sharing, adaptation, distribution and reproduction in any medium or format, as long as you give appropriate credit to the original author(s) and the source, provide a link to the Creative Commons licence, and indicate if changes were made. The images or other third party material in this article are included in the article's Creative Commons licence, unless indicated otherwise in a credit line to the material. If material is not included in the article's Creative Commons licence and your intended use is not permitted by statutory regulation or exceeds the permitted use, you will need to obtain permission directly from the copyright holder. To view a copy of this licence, visit http://creativecommons.org/licenses/by/4.0/. 


\section{Background}

Parkinson's disease (PD) is a progressive multi-system, neurodegenerative disease that leads to both motor and non-motor symptoms (Sveinbjornsdottir, 2016; Kalia \& Lang, 2015). The most common motor symptoms include tremor, bradykinesia, rigidity, and postural instability. Non-motor symptoms include pain, orthostatic hypotension, urinary disturbances, sleep disorders, and various neuropsychiatric symptoms. Both sets of symptoms have significant impact on PD patients' quality of life and mortality (Sveinbjornsdottir, 2016; Sauerbier et al., 2016; Martinez-Martin, 2011). The wide array of PD symptoms has been shown to alter family relationships, lead to a loss of self-identity, and contribute toward a sense of being deprived of one's self-worth (Sjödahl Hammarlund et al., 2018). Therapeutic options aimed at alleviating PD symptoms are thus vital for disease management.

Though the exact cause of PD continues to be studied today, there exist two governing markers underlying the pathophysiology of the disease process. These include the degeneration of dopaminergic neurons in the nigrostriatal pathway, and the presence of intracytoplasmic proteinaceous inclusion bodies in surviving neurons, referred to as Lewy bodies. The degeneration of dopaminergic neurons in the nigrostriatal pathway is thought to reduce inhibition of the thalamus and decrease excitatory input to the motor cortex, ultimately leading to bradykinesia and other PD symptoms (Blandini, 2013; Dauer \& Przedborski, 2003). The decrease in dopaminergic neural firing in the nigrostriatal pathway may disrupt the neural oscillations in the basal ganglia. Specifically, it may lead to increased firing of striatal neurons in the indirect pathway, with the recruited neurons firing with an excess of beta $(13-30 \mathrm{~Hz})$ oscillations in the motor system (Beudel et al., 2019). The two mainstay therapies of PD, dopamine and deep brain stimulation (DBS), have both been shown to alter the pathological changes in electrical oscillations (Kühn et al., 2006; Eusebio et al., 2011).

Though dopamine and DBS are the gold standard treatment for PD, they both continue to have severe limitations and side effects to consider. For dopamine treatment, side effects include dyskinesias, GI disturbances, orthostatic hypotension, and neuropsychiatric features including anxiety and hallucinations (Connolly \& Lang, 2014). While it is possible to adjust dosing parameters to ameliorate some of the side effects above, one of the more prominent issues is that dopamine agonists are associated with loss of efficacy over time (LeWitt et al., 2019). DBS has been shown to have excellent outcomes in alleviating some of the motor and non-motor symptoms of PD (Okun, 2012; De Hemptinne et al., 2015; Fasano et al., 2012). However, there are several associated risks with DBS, including intracranial bleeding (up to 5.0\%), hardware issues, infection, incorrect placement, mis-positioning, and seizures (up to 2.4\%) (Okun, 2012; Larson, 2014). The risk of infection has been reported to range from 1.2 to $15.2 \%$ (Okun, 2012). Similar to dopamine treatment, the use of DBS may have decreased efficacy over time as well (Paschen et al., 2019).

An alternate therapy that can be used to alleviate both motor and non-motor symptoms of PD is spinal cord stimulation (SCS) technology. Spinal cord stimulation of the dorsal columns within the epidural space has already been shown to be beneficial in a multitude of pain conditions (Jeon, 2012; Verrills et al., 2016). SCS has been shown to stimulate large non-nociceptive myelinated fibers of the peripheral nerves (A- $\beta$ fibers), leads to inhibition of the small nociceptive projections (A- $\delta$ and $C$ ) in the dorsal horn. Additionally, SCS may lead to the release of GABA, substance-P and serotonin, neurotransmitters involved in pain modulation (Jeon, 2012). The new therapy has also been shown to improve the motor symptoms of PD (de Andrade et al., 2016; Samotus et al., 2018). Thus, SCS may be an excellent therapeutic option to alleviate both motor symptoms and nonmotor symptoms such as pain in PD patients. Whether to use SCS as a singular bioelectric therapy option or as a salvage therapy after dopamine and DBS treatments have begun to lose efficacy, continues to be a question of interest. There have been studies that have shown SCS to be a reasonable salvage option after dopamine and DBS (Pinto de Souza et al., 2017). However, with any therapy the risks must be considered. Risks for SCS include undesirable feelings such as a jolt or shock, hematoma, infection, seroma, and in extreme cases, epidural hemorrhage (Medtronic, 2020). The data thus far point to SCS as being a viable alternative, conjunctive and or potential salvage therapy for those with PD. This paper aims to analyze clinical translational data for SCS in PD as both singular bioelectric therapy and salvage therapy after loss of efficacy of DBS for both motor and non-motor symptoms such as pain.

\section{Methods}

\section{Subjects}

In this non-randomized study, a total of $15 \mathrm{PD}$ patients were recruited through a convenience sampling method, whose pain was refractory to medical therapy and other conservative treatments. The etiology of pain was determined by history and neurological physical findings, imaging diagnosis using MRI and $\mathrm{CT}$, and responsiveness to nerve block and medications. The study was approved by the Institutional Review Boards at each respective center. The PI and sub-investigators referred subjects to the study from their own practices, if the patients were eligible to be implanted with the SCS system and were 
interested in participation. Patients were included in the study if they had chronic pain of predominantly neuropathic origin that was refractory to conventional treatments such as analgesic drugs and nerve blocks. In addition, patients were eligible if their pain had not improved even with adequate dopaminergic drug administration and adjustment of DBS parameters (if the patients had previously received DBS). Most patients had fluctuating pain in conjunction with motor fluctuations. For example, the patients' pain increased when they were off dopaminergic drugs and/or when DBS was turned off. Overall, the causes of pain in the patients enrolled in this study were as follows: 5 cases after lumbar spine surgery, 4 cases of radicular pain due to compression fractures (spinal surgery was not indicated because of severe osteoporosis or spinal scoliosis), 1 case of radicular pain due to severe spinal scoliosis, 3 cases of postural abnormalities (in this group pain occurred by standing for a long time with scoliosis and bent posture), and 2 cases with unknown etiology (Table 1). Exclusion criteria included: 1) active suicidal ideation, 2) substance abuse/addiction history, 3) chronic illness / cancer diagnosis, 4) life-threatening illness, 5) implanted devices such as a cardiac pacemaker, and 6) participating in another clinical study. DBS was not included in the exclusion criteria.

\section{SCS intervention}

A total of 15 patients were included in the study with a mean age of 74 (SD 5.2) and an average PD duration of 17 years (SD 8.7) (Table 1). All participants had a history of concurrent pain conditions. Seven patients had no DBS therapy prior to the study, while 8 had undergone DBS prior to initiation. One or two percutaneous electrodes were implanted in the epidural space on the dorsal midline at the level of the thoracic or cervical spine and connected to an implantable pulse generator (Abbott Proclaim Elite5 or Abbott Prodigy); 1 Abbott Lamitrode lead in 5 patients, 1 Abbott Octrode lead in 1 patient, 2 Abbott Octrode leads in 3 patients, 1 Abbott Octrode lead with 1 Abbott Lamitrode lead in 4 patients, and 2 Medtronic Octad leads in 2 patients, in which a Medtronic IPG was previously used and changed to an Abbott IPG with a conversion connector. Lead choice (e.g, company and type of lead used) was determined based on differing protocols of the Japanese hospital systems. Participants were set to one of three stimulation modes according to their preference: the continuous tonic stimulation, the continuous Burst stimulation (40 $\mathrm{Hz}, 500 \mathrm{~Hz}, 1000 \mu \mathrm{s}$ ), or the cycle mode (on time of 10 $15 \mathrm{~s}$, off time of $15-30 \mathrm{~s})$ with Burst $(40 \mathrm{~Hz}, 500 \mathrm{~Hz}$, $1000 \mu \mathrm{s})$. While traditional spinal cord stimulation has been delivered in a tonic fashion, the majority of patients in this study opted for the relatively newer, "burst SCS" in either a continuous or cycle mode timeframe. The burst SCS stimulation, demonstrated by De Ridder, is characterized by a five-pulse train with an intraburst frequency of $500 \mathrm{~Hz}$, with a $40 \mathrm{~Hz}$ passive recharging model. In order to ensure proper electrode placement, a low-frequency tonic stimulation was first applied to induce a paresthesia or alternate sensory experience such as tingling in the primary area of the patient's pain (e.g, lower back). Next, the stimulation waveform was changed to the stimulation parameter that the patient had chosen (e.g, burst stimulation, burst stimulation with cycle mode, tonic stimulation). The intensity of the stimulation was set to $60-70 \%$ of the threshold for paresthesias evoked by burst during intraoperative testing. All patients did not feel stimulation-induced paresthesias after the intensity was reduced to $60-70 \%$ of the threshold for paresthesias, except for one patient who chose either the continuous tonic $(2.6 \mathrm{~mA}, 10 \mathrm{~Hz}, 350 \mu \mathrm{s})$ or the continuous Burst $(0.15 \mathrm{~mA})$ stimulation based on his severity of pain. The patients had different levels of pain that were altered by the action of both dopaminergic drugs and DBS. Therefore, the effects of SCS were evaluated "on-medication" and "on-DBS" under the condition that the dopaminergic drugs and DBS were sufficiently controlled so that there were no off-period painful sensations. The careful and adequate administration of dopaminergic drugs (or DBS programming) prevented the appearance of off-period painful sensations and controlled other motor and non-motor symptoms in Parkinson's disease. In total, there were 8 patients who had previously received DBS and 7 patients who received only drug treatment (anti-Parkinsonian drugs and other agents for neuropathic pain). All patients underwent bilateral subthalamic deep brain stimulation (STN-DBS). Patients who received DBS were combined with antiParkinson drugs medication. In patients who received DBS, the therapeutic effect of SCS was evaluated at "onmedication" and "on-DBS". In patients who received only drug therapy, the therapeutic effect of SCS was evaluated in the "on-medication" state. The exact

Table 1 Demographic Information

\begin{tabular}{|c|c|c|c|c|c|c|c|}
\hline $\mathrm{N}$ & Average age & Average PD duration $(Y)$ & Type of PD initially & Indication for SCS & DBS prior & Leads and location & Follow up period (months) \\
\hline \multirow[t]{3}{*}{15} & 74 & 17 & Tremor Dominant: 2 & Pain multiple sites: 7 & No: 7 & Thoracic: 14 & Range: 4-33 \\
\hline & & & Akinetic Rigid: 13 & Low back pain only: 6 & Yes: 8 & Cervical: 1 & Average: 22 \\
\hline & & & & Leg Pain: 2 & & & \\
\hline
\end{tabular}


Table 2 Lead locations and stimulation parameters

\begin{tabular}{|c|c|c|c|}
\hline Patient & $\begin{array}{l}\text { DBS } \\
\text { prior }\end{array}$ & $\begin{array}{l}\text { Lead } \\
\text { locations }\end{array}$ & Stimulation parameter \\
\hline 1 & No & $\begin{array}{l}\text { T7-T9 } \\
\text { T10-T12 }\end{array}$ & $\begin{array}{l}\text { Proclaim Elite5 (Abbott), 5-6-(at T8 level) 9-(at T10 level) } 15+16+\text { (at T12 level), } 0.5 \mathrm{~mA} \text { Burst ( } 40 \mathrm{~Hz}, 500 \mathrm{~Hz}, 1000 \mathrm{us} \text { ), } \\
\text { Cycle mode (on time } 15 \mathrm{~s} \text {, off time } 15 \mathrm{~s} \text { ) }\end{array}$ \\
\hline 2 & No & $\begin{array}{l}\text { T8-9 } \\
\text { T10-11 }\end{array}$ & Prodigy (Abbott), 3-8+, $0.5 \mathrm{~mA}$, Burst ( $40 \mathrm{~Hz}, 500 \mathrm{~Hz}, 1000 \mathrm{us})$ \\
\hline 3 & No & $\mathrm{C} 2-\mathrm{C} 5$ & Proclaim Elite5 (Abbott), 2-4+, $0.4 \mathrm{~mA}$, Burst ( $40 \mathrm{~Hz}, 500 \mathrm{~Hz}, 1000 \mathrm{us}$ ), Cycle mode (on time 30s, off time $90 \mathrm{~s}$ ) \\
\hline 4 & No & T6-T8 & Proclaim Elite5 (Abbott), 3-4-12+13+, 0.8 mA, Burst ( $40 \mathrm{~Hz}, 500 \mathrm{~Hz}, 1000 \mathrm{us})$ \\
\hline 5 & No & $\begin{array}{l}\mathrm{T} 10-\mathrm{T} 11 \\
\mathrm{~T} 11-\mathrm{T} 12\end{array}$ & Proclaim Elite5 (Abbott), 15-16-(at T12 level) $11+12+$ (at T10 level) 0.15 mA, Burst ( $40 \mathrm{~Hz}, 500 \mathrm{~Hz}, 1000 \mathrm{us}$ ) \\
\hline 6 & No & T8-T10 & Proclaim Elite5 (Abbott), 2-10-(at T8/9 level) $3+11+$ (at T9 level) 0.15 mA, Burst ( $40 \mathrm{~Hz}, 500 \mathrm{~Hz}$, 1000us) \\
\hline 7 & No & T9-T11 & $\begin{array}{l}\text { Proclaim Elite5 (Abbott), } 2-4+\text { (at T9/10 level) } 2.6 \mathrm{~mA} \text {, tonic } 2.6 \mathrm{~mA} 10 \mathrm{~Hz} 350 \mathrm{us} \text { or } 0.15 \mathrm{~mA} \text {, Burst }(40 \mathrm{~Hz}, 500 \mathrm{~Hz} \text {, } \\
\text { 1000us), (Switching from Burst mode to tonic SCS mode when severe pain is occurred) }\end{array}$ \\
\hline 8 & Yes & $\begin{array}{l}\text { T8-T9 } \\
\text { T10-T11 }\end{array}$ & Proclaim Elite5 (Abbott), 1-2-7 + 8+, $1.45 \mathrm{~mA}$, Burst ( $40 \mathrm{~Hz}, 500 \mathrm{~Hz}, 1000 \mathrm{us}$ ), Cycle mode (on time 10s, off time $30 \mathrm{~s}$ ) \\
\hline 9 & Yes & T7-T9 & $\begin{array}{l}\text { Proclaim Elite5 (Abbott), 6-7 +13-14-15+16+, } 0.6 \mathrm{~mA} \text {, Burst ( } 40 \mathrm{~Hz}, 500 \mathrm{~Hz}, 1000 \mathrm{us}) \text {, Cycle mode (on time 10s, off } \\
\text { time } 30 \mathrm{~s} \text { ) }\end{array}$ \\
\hline 10 & Yes & T9-T10 & $\begin{array}{l}\text { Proclaim Elite5 (Abbott), 3-2 + 4+ (at T9/10 level), } 0.40 \text { mA, Burst ( } 40 \mathrm{~Hz}, 500 \mathrm{~Hz}, 1000 \mathrm{us}) \text {, Cycle mode (on time 30s, off } \\
\text { time } 90 \mathrm{~s} \text { ) }\end{array}$ \\
\hline 11 & Yes & T9-T10 & Proclaim Elite5 (Abbott), 2-1 + 3+ (at T9 level), 0.20 mA, Burst ( 40 Hz, 500 Hz, 1000us) \\
\hline 12 & Yes & T6-T9 & $\begin{array}{l}\text { Proclaim Elite } 5 \text { (Abbott), 10-12+ (at T7 level), } 0.80 \text { mA, Burst ( } 40 \mathrm{~Hz}, 500 \mathrm{~Hz}, 1000 \mathrm{us}) \text {, Cycle mode (on time 30s, } \\
\text { off time } 90 \mathrm{~s} \text { ) }\end{array}$ \\
\hline 13 & Yes & $\begin{array}{l}\text { T5-T7 } \\
\text { T9-T11 }\end{array}$ & Proclaim Elite5 (Abbott), $11-10+12+$ (at T9/10 level), $3.0-4.5 \mathrm{~mA}$, tonic $40 \mathrm{~Hz} 350 \mathrm{us}$ \\
\hline 14 & Yes & T2-T4 & Proclaim Elite5 (Abbott),4-5-6 + 7+ (at T3 level), 0.75 mA, Burst ( $40 \mathrm{~Hz}, 500 \mathrm{~Hz}, 1000 \mathrm{us})$ \\
\hline 15 & Yes & $\begin{array}{l}\text { T9-T10 } \\
\text { T10-T11 }\end{array}$ & $\begin{array}{l}\text { Proclaim Elite }(\text { (Abbott), } 11-13+\text { (at T9/10 level), } 0.35 \text { mA, Burst ( } 40 \mathrm{~Hz}, 500 \mathrm{~Hz}, 1000 \mathrm{us} \text { ), Cycle mode (on time } 15 \mathrm{~s} \text {, off } \\
\text { time } 45 \mathrm{~s} \text { ) }\end{array}$ \\
\hline
\end{tabular}

configuration for each patient and stimulation parameters can be found in Table 2 .

\section{Clinical outcomes}

Patients were asked to complete the Visual Analogue Scale for pain (VAS), the revised Unified Parkinson's Disease Rating Scale (MDS-UPRS), Self-Rating Depression Scale (SDS), Hamilton Depression Rating Scale (HAMD), Profile of Mood State (POMS-II), 10 M (10meter) walking test, and a Timed Up and Go (TUG) at each clinic visit. Each participant had a family member or close friend present during clinic visits to help answer questionnaires.

\section{Statistical analysis}

Mean and standard deviations were calculated for two separate groups, those who had DBS prior to entering the study, and those that did not. Paired two-tailed ttests were calculated comparing pre-intervention means and post-intervention means within each group (Table 3 ). As a sensitivity analysis, we also performed a Wilcoxon sign rank test for certain parameters.

\section{Results}

All patients in the study experienced significant improvement in VAS pain scores after implantation of SCS (two-tailed t-test, $p<0.005$ ) (Table 3, Fig. 1). Specifically,

Table 3 Outcome measures pre and post stimulation therapy

\begin{tabular}{|c|c|c|c|c|c|}
\hline Outcome & $\begin{array}{l}\text { DBS prior / stimulation } \\
\text { parameter }\end{array}$ & Pre stimulation (SD) & Post stimulation (SD) & $P$-value ${ }^{1}$ & Sample size (n) \\
\hline \multirow[t]{2}{*}{ VAS scores } & No & $8.9(1.4)$ & $3.8(2.6)$ & $0.0007^{2}$ & 7 \\
\hline & Yes & $8.5(1.4)$ & $3.3(2.5)$ & $.0001^{2}$ & 8 \\
\hline \multirow[t]{2}{*}{ VAS scores } & Continuous burst & $9.4(0.8)$ & $4.9(2.5)$ & 0.002 & 6 \\
\hline & Cycle mode burst & $7.8(1.4)$ & $2.6(2.0)$ & .0001 & 7 \\
\hline
\end{tabular}




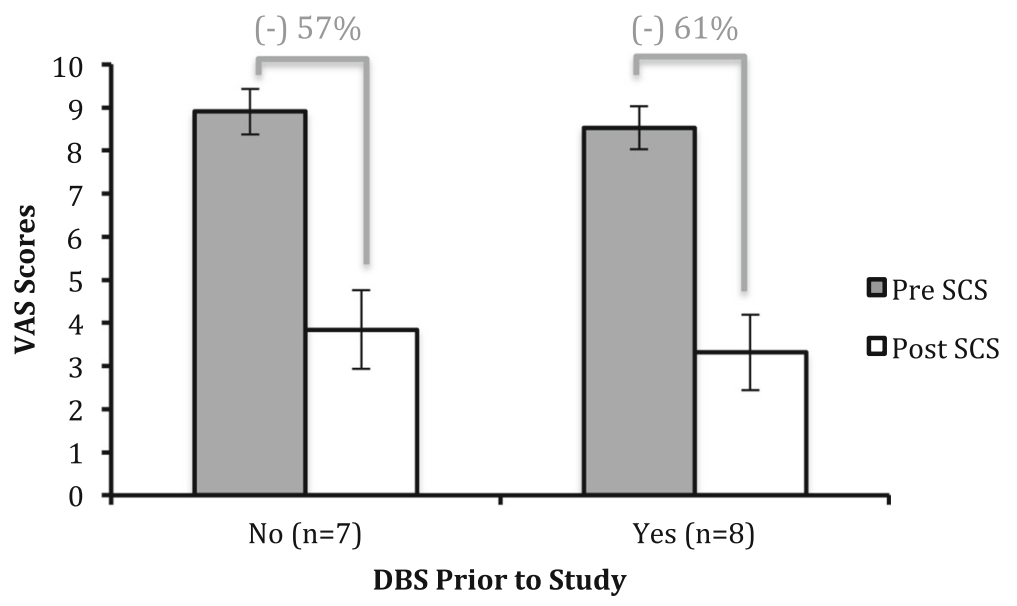

Fig. 1 Pre and Post VAS Scores Stratified by DBS Prior to Study

for patients who did not receive DBS prior to SCS, the average percent reduction was 57\% (two-tailed t-test, $p<0.0007)$, and for those who did receive DBS, the average percent reduction was $61 \%$ (two-tailed t-test, $p<$ 0.0001). As a sensitivity analysis, we also performed a Wilcoxon sign ranked test, which also found a $p$ value of $<0.05$. Additionally, we found that those patients who chose the cycling burst stimulation parameter had an average 67\% reduction in VAS scores, as compared to the continuous burst parameter group, which had an average $48 \%$ reduction in VAS scores (Fig. 2). The effects of SCS for neuropathic pain did not differ between the "Meds+SCS" group and the "Meds+DBS + SCS" group. When comparing the mean differences for the 10-meter walk and the TUG before and after SCS therapy, there was no statistically significant difference between groups (Table 3). However, out of the 11 total patients who were able to complete the 10-meter walk before and after therapy, 8 of them (73\%) showed improvement in their completion time, with an average improvement of $12 \%$ (two-tailed paired t-test, $p=0.003$ ) (Supplementary Figure 1). Out of the 11 patients who completed the TUG, 7 of them (64\%) showed clinically significant improvement in their completion time with an average improvement of $21 \%$ (two-tailed paired t-test, $p=0.03$ ) (Supplementary Figure 2). When stratifying by stimulation parameters, those who chose a continuous burst pattern had an 18\% improvement in TUG scores, while those who chose cycling mode burst stimulation had a 7\% worsening in scores (Supplementary Figure 3). MDS-UPRS, SDS, and Hoehn and Yahr scores did not differ between pre and post SCS stages. For those that had not receive DBS prior to the study, HAMD and POMS-II scores increased, while for those who had received DBS prior, both HAMD and POMS-II scores decreased (Supplementary Table 1). However, given the low number of patients who fully completed these assessments, the standard deviation for each of these parameters was relatively high.

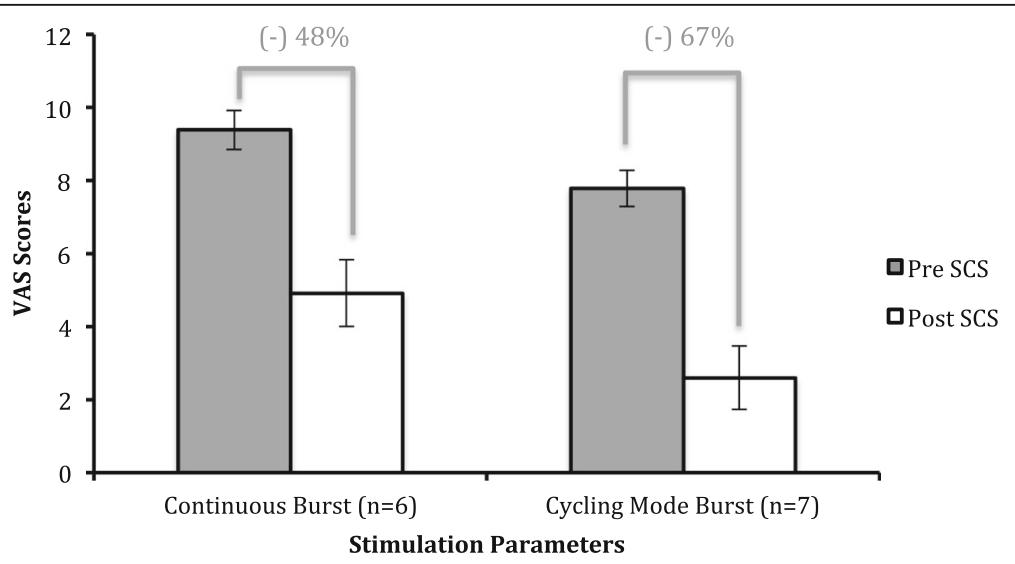

Fig. 2 Pre and Post VAS Scores Stratified by Stimulation Parameters 


\section{Discussion}

Motor symptoms such as tremor, bradykinesia, rigidity, and postural instability, as well as concurrent pain symptoms significantly impact PD patients' quality of life. SCS is an emerging technology that can potentially be utilized to treat both the motor and nonmotor symptoms such as pain that patients with PD deal with on a daily basis. There are many theories as to how burst SCS leads to an improvement in motor function in patients with $\mathrm{PD}$, and there continues to be ongoing research in the area. While some neurons within the dorsal column generate single action potentials, other neurons in the region fire in a burst of action potentials. These bursts are thought to lead to variations in downstream modulation of the lateral and medial spinothalamic tracts (Chakravarthy et al., 2019). In a preclinical study involving rat models, Remy and Spruston delivered a single burst stimulation to the Schaffer collateral pathway in the hippocampus, which produced long term potentiation (LTP) at the neural synapse between the collaterals and postsynaptic CA1 neurons (Remy \& Spruston, 2007). This study showed the potential for burst SCS to produce long lasting changes to neural networks involved in the pain networks of the central nervous system. It has also been shown through animal models that burst SCS, unlike tonic SCS, does not evoke alteration in the dorsal column nuclei, such as the gracile nucleus, a possible mechanism for reduced paresthesias seen with burst SCS. Preclinical studies have also shown burst SCS to depress wide dynamic range (WDR) neurons within the dorsal horns, which may be a key component in SCS's mechanism for pain reduction (Crosby et al., 2015). Clinically, SCS has been thought to stimulate the superficial fibers of the dorsal column, which in turn can lead to the increased release of dopamine (Fuentes et al., 2010; Shon et al., 2010). Other theories suggest that SCS can lead to a more neuroprotective role, decreasing the rate of dopaminergic degeneration (Fuentes et al., 2010; Gubellini et al., 2009). Falowski et al. measured somatosensory evoked potentials (SSEPs) from different types of SCS waveforms (e.g. tonic, burst etc) and found that burst stimulation inhibited somatic sensory transduction, and tended to activate distal muscles from the site of stimulation at lower amplitudes and proximal muscles with higher amplitudes (Falowski, 2019). The group found the opposite finding for lower frequency tonic stimulation, indicating that burst SCS and tonic SCS differ in modulation of fibers within the dorsal column.

There have been very few studies that have tested whether SCS can lead to improvement in motor function and concurrent pain in patients with PD. A previous case report showed that SCS placed in the thoracic epidural space (T9-10) level, led to improvement in motor function in PD patients. In the current study, 14/15 subjects had SCS placed in the thoracic epidural space. While the mean differences between pre SCS implantation and post SCS implantation groups for motor function (10 M walk, TUG) were not statistically different, most patients that were able to complete the tests showed improvement in their completion times for both tasks. Additionally, after removal of outliers, there was a statistically significant improvement in motor function for both groups (Table 3). However, given the study design, it is not possible to differentiate whether these motor improvements stemmed from the effects of SCS, or if the decrease in pain allowed patient to improve their motor testing results. Thus, additional studies need to be conducted to explore the efficacy of SCS placed in the thoracic epidural space to help alleviate PD motor symptoms, and to explore the causal relationships between the SCS, pain and motor improvement.

SCS could be utilized even after DBS treatment in our study and led to significant pain relief in PD patients. SCS after failed DBS therapy was also able to help a subset of patients in our cohort with motor symptoms, though the difference between the groups as a whole did not show statistical significance. Future studies should be conducted that analyze the use of SCS as a salvage therapy for Parkinson's disease symptoms after failed DBS therapy.

There are several limitations to this study. The patients did not receive the spinal cord stimulator in the exact same spinal location due to differences in presenting pain symptoms. Additionally, not every patient was able to return and complete the TUG and $10 \mathrm{M}$ walk test, which decreased the sample size. However, the majority of patients still had leads placed in the thoracic spine, and the majority of patients were able to complete the questionnaires and tests given in the study. We believe that the data in this study can be helpful to guide future studies that utilize SCS as salvage therapy for Parkinson's disease to improve the body of literature on the use of SCS in $\mathrm{PD}$ patients.

\section{Conclusions}

In this study, all patients showed a statistically significant improvement in VAS pain scores after receiving SCS. The majority of patients also showed improvements in motor functioning after SCS even after failed DBS therapy. This study thus points to the potential utility of SCS as an option to address both pain and motor symptoms in PD patients who have and have not received DBS therapy. 


\section{Supplementary information}

Supplementary information accompanies this paper at https://doi.org/10. 1186/s42234-020-00055-3.

Additional file 1: Supplementary Figure 1. Pre and Post SCS Result for 10 Meter Walk in Patients who Responded

Additional file 2: Supplementary Figure 2. Pre and Post Spinal Cord Stimulation TUG Results

Additional file 3: Supplementary Figure 3. Pre and Post Stimulation TUG Scores Stratified by Stimulation Parameters

Additional file 4: Supplementary Table 1. Other Clinical

Characteristics Pre and Post Stimulation

\section{Abbreviations}

PD: Parkinson's Disease; DBS: Deep brain stimulation; VAS: Visual Analogue Scale; TUG: Timed Up and Go; SCS: Spinal cord stimulation; MDSUPRS: Unified Parkinson's Disease Rating Scale; SDS: Self-Rating Depression Scale; HAMD: Hamilton Depression Rating Scale; POMS-II: Profile of Mood State; 10 M: 10 M (10-meter) walking test; WDR: Wide dynamic range; SSEPs: Somatosensory evoked potentials

\section{Acknowledgements}

The authors have no further acknowledgements to report.

\section{Authors' contributions}

All authors were involved in the development, writing, and analysis of this manuscript. The author(s) read and approved the final manuscript.

\section{Funding}

The authors declare no financial support with regards to this body of work.

\section{Availability of data and materials}

The datasets used and/or analysed during the current study are available from the corresponding author on reasonable request.

\section{Ethics approval and consent to participate}

The study was approved by the Institutional Review Board at each respective center.

\section{Consent for publication}

All participants were consented to the study and all information has been de-identified prior to publication.

\section{Competing interests}

Dr. Chakravarthy is a consultant to Abbott, Bioness, Medtronic, Nalu Medical, Saluda Medical. He has stock options in Nalu Medical. He is also founder of Newrom Biomedical. Dr. Iwamuro's workplace, The Department of Research and Therapeutics for Movement Disorders at the Juntendo University Graduate School of Medicine, is an endowment department supported with an unrestricted grant from Medtronic, Boston Scientific, Kyowa Kirin, Boehringer Ingelheim, AbbVie and FP Pharmaceutical. Dr. Ayano Matsui has received honoraria for lectures and writing about SCS from Abbott Medical Japan. There are no other reported conflicts of interest for this body of work from the other authors.

\section{Author details}

'Division of Pain Medicine, Department of Anesthesiology, University of California San Diego Health Center, 9400 Campus Point Dr, La Jolla, San Diego, CA, USA. VA San Diego Health Care, 3350 La Jolla Village Dr, San Diego, CA, USA. ${ }^{3}$ Department of Neurosurgery, Tokyo Metropolitan Neurological Hospital, Tokyo, Japan. ${ }^{4}$ Department of Research and Therapeutics for Movement Disorders, Juntendo University Graduate School of Medicine, Tokyo, Japan. ${ }^{5}$ Department of Orthopedics, National Center Hospital of Neurology and Psychiatry, Tokyo, Japan.
Received: 12 July 2020 Accepted: 27 August 2020

Published online: 28 September 2020

\section{References}

Beudel M, Sadnicka A, Edwards M, De Jong BM. Linking pathological oscillations with altered temporal processing in Parkinsons disease: neurophysiological mechanisms and implications for neuromodulation. Front Neurol. 2019;10:462.

Blandini F. Neural and immune mechanisms in the pathogenesis of Parkinson's disease. J Neurolmmune Pharmacol. 2013:8(1):189-201.

Chakravarthy K, Fishman MA, Zuidema X, Hunter CW, Levy R. Mechanism of action in burst spinal cord stimulation: review and recent advances. Pain Med. 2019;20(Supplement 1):S13-22

Connolly BS, Lang AE. Pharmacological treatment of Parkinson disease: a review. JAMA. 2014;311(16):1670-83.

Crosby ND, Goodman Keiser MD, Smith JR, Zeeman ME, Winkelstein BA. Stimulation parameters define the effectiveness of burst spinal cord stimulation in a rat model of neuropathic pain. Neuromodulation. 2015;18(1):1-8.

Dauer W, Przedborski S. Parkinson's disease: mechanisms and models. Neuron. 2003;39(6):889-909.

de Andrade EM, Ghilardi MG, Cury RG, Barbosa ER, Fuentes R, Teixeira MJ, et al. Spinal cord stimulation for Parkinson's disease: a systematic review. Neurosurg Rev. 2016:39(1):27-35.

De Hemptinne C, Swann NC, Ostrem JL, Ryapolova-Webb ES, San Luciano M, Galifianakis NB, et al. Therapeutic deep brain stimulation reduces cortical phase-amplitude coupling in Parkinson's disease. Nat Neurosci. 2015;18(5): 779-86.

Eusebio A, Thevathasan W, Doyle Gaynor L, Pogosyan A, Bye E, Foltynie T, et al. Deep brain stimulation can suppress pathological synchronisation in parkinsonian patients. J Neurol Neurosurg Psychiatry. 2011;82(5):569-73.

Falowski SM. An observational case series of spinal cord stimulation waveforms visualized on intraoperative neuromonitoring. Neuromodulation. 2019;22(2): 219-28.

Fasano A, Daniele A, Albanese A. Treatment of motor and non-motor features of Parkinson's disease with deep brain stimulation. Lancet Neurol. 2012;11(5):429-42.

Fuentes R, Petersson P, Nicolelis MAL. Restoration of locomotive function in Parkinson's disease by spinal cord stimulation: mechanistic approach. Eur J Neurosci. 2010;32(7):1100-8

Gubellini P, Salin P, Kerkerian-Le Goff L, Baunez C. Deep brain stimulation in neurological diseases and experimental models: from molecule to complex behavior. Prog Neurobiol. 2009;89(1):79-123.

Jeon YH. Spinal cord stimulation in pain management: a review. Korean J Pain 2012:25(3):143-50

Kalia LV, Lang AE. Parkinson's disease. Lancet. 2015;386(9996):896-912.

Kühn AA, Kupsch A, Schneider GH, Brown P. Reduction in subthalamic 8-35 Hz oscillatory activity correlates with clinical improvement in Parkinson's disease. Eur J Neurosci. 2006;23(7):1956-60.

Larson PS. Deep brain stimulation for movement disorders. Neurotherapeutics. 2014;11(3):465-74.

LeWitt PA, Giladi N, Navon N. Pharmacokinetics and efficacy of a novel formulation of carbidopa-levodopa (Accordion Pill ${ }^{\oplus}$ ) in Parkinson's disease. Parkinsonism Relat Disord. 2019;65:131-8.

Martinez-Martin P. The importance of non-motor disturbances to quality of life in Parkinson's disease. J Neurol Sci. 2011:310(1-2):12-6.

Medtronic. Indications, safety, and warnings spinal cord stimulation [Internet]. 2020 [cited 8 May 2020]. Available from: https://www.medtronic.com/us-en/ healthcare-professionals/therapies-procedures/neurological/spinal-cordstimulation/indications-safety-warnings.htm|\#: :text=ADVERSEEVENTS,relief\%2 Candothersurgicalrisks.

Okun MS. Deep-brain stimulation for Parkinson's disease. N Engl J Med. 2012 367(16):1529-38

Paschen S, Forstenpointner J, Becktepe J, Heinzel S, Hellriegel H, Witt K, et al. Long-term efficacy of deep brain stimulation for essential tremor: an observer-blinded study. Neurology. 2019;92(12):e1378-86.

Pinto de Souza C, Hamani C, Oliveira Souza C, Lopez Contreras WO, dos Santos Ghilardi MG, Cury RG, et al. Spinal cord stimulation improves gait in patients with Parkinson's disease previously treated with deep brain stimulation. Mov Disord. 2017;32(2):278-82

Remy S, Spruston N. Dendritic spikes induce single-burst long-term potentiation. Proc Natl Acad Sci U S A. 2007;104(43):17192-7.

Samotus O, Parrent A, Jog M. Spinal cord stimulation therapy for gait dysfunction in advanced Parkinson's disease patients. Mov Disord. 2018;33(5):783-92. 
Sauerbier A, Jenner P, Todorova A, Chaudhuri KR. Non motor subtypes and Parkinson's disease. Parkinsonism Relat Disord. 2016;22(Supplement 1):S41-6.

Shon YM, Lee KH, Goerss SJ, Kim IY, Kimble C, Van Gompel JJ, et al. High frequency stimulation of the subthalamic nucleus evokes striatal dopamine release in a large animal model of human DBS neurosurgery. Neurosci Lett. 2010;475(3):136-40.

Sjödahl Hammarlund C, Westergren A, Åström I, Edberg AK, Hagell P. The impact of living with Parkinson's disease: balancing within a web of needs and demands. Park Dis. 2018.

Sveinbjornsdottir S. The clinical symptoms of Parkinson's disease. J Neurochem. 2016;139(Supplement 1):318-24.

Verrills P, Sinclair C, Barnard A. A review of spinal cord stimulation systems for chronic pain. J Pain Res. 2016;9:481-92.

\section{Publisher's Note}

Springer Nature remains neutral with regard to jurisdictional claims in published maps and institutional affiliations.

Ready to submit your research? Choose BMC and benefit from:

- fast, convenient online submission

- thorough peer review by experienced researchers in your field

- rapid publication on acceptance

- support for research data, including large and complex data types

- gold Open Access which fosters wider collaboration and increased citations

- maximum visibility for your research: over $100 \mathrm{M}$ website views per year

At BMC, research is always in progress.

Learn more biomedcentral.com/submissions 